\title{
Condições ergonômicas dos trabalhadores em galpões de frangos de corte durante a fase de aquecimento
}

\author{
Cinara da C. S. Carvalhoㅇ, Cecília de F. Souza ${ }^{2}$, Ilda de F. F. Tinoco ${ }^{2}$, \\ Maria de F. A. Vieira ${ }^{2}$, Irene Menegali ${ }^{3} \&$ Claudia R. dos Santos ${ }^{2}$
}

\begin{abstract}
RESU M 0
A adoção das práticas de bem-estar durante o processo de criação animal tem ganhado maiores espaços devido à comprovada melhora na produção. Hoje, a condição de bem-estar pode ser estendida também para o humano que, tendo boas condições de trabalho acaba, assim, por refletir em um manejo de sucesso dos animais. Buscando atender a essa nova tendência do mercado objetivou-se, com este trabalho, avaliar as condições ergonômicas e a salubridade do ambiente de galpões de frangos de corte equipados com três diferentes sistemas de ventilação mínima (positiva, negativa e natural) no que se refere à saúde do trabalhador. Com base nos efeitos dos sistemas de ventilação mínima avaliou-se carga física de trabalho, qualidade do ar, ambiente térmico, nível de ruído e iluminação, além da análise postural e biomecânica. De posse dos dados analisados verificou-se que o galpão equipado com sistema de ventilação positiva possuía um ambiente de maior salubridade para o trabal hador. Independente do sistema de ventilação utilizado, atividades como abastecimento manual do comedouro, limpeza de bebedouros e revolvimento da cama, podem oferecer riscos de lesão corporal em virtude da forma como são executados.
\end{abstract}

Palavras-chave: avicultura, ergonomia, ventilação mínima

\section{Ergonomic conditions of workers in poultry houses during the heating phase}

\begin{abstract}
A B STRACT
The adoption of the practices of well-being in animal husbandry has gained increased space due to proven improvement in production. Today, the condition of well being, may be extended to the human beings, that having good working conditions may reflect in a successful management of animals. Seeking to meet this new market trend, the aim of this study was to evaluate the ergonomic conditions of the environment and health in broiler sheds, equipped with three different minimal ventilation systems (positive, negative and natural) regarding workers' health. A ssociated with the effects of minimum ventilation systems evaluated the physical load of work, air quality, thermal environment, noise level and lighting besides postural and biomechanical analysis. After the data analysis, it was found that the shed equipped with positive ventilation system had an environment favorable for workers' health. Regardless of the ventilation system used, activities such as manual supply of feeder, cleaning of drinking water system and turning of the bed, may present risks of injury depending on how these activities are executed.
\end{abstract}

Key words: poultry, ergonomics, minimum ventilation

\footnotetext{
Unimontes, Avenida Reinaldo Viana, 2630, Bico da Pedra, CEP 39440-000, Janaúba, MG. Fone: (38) 3821-1378. E-mail: cinara.carvalho@unimontes.br

2 UFV, Avenida P.H. Rolfs, s/n, Centro, CEP 36570-000, Viçosa, MG. Fone: (31) 3899-2729. E-mail: cfsouza@ufv.br; iftinoco@ufv.br; fatimaaraujo.vieira@yahoo.com.br; crsantos74@yahoo.com.br

${ }^{3}$ U FMG, A venida U niversitária, 1.000, Bairro Universitário, CEP 39404-547, Montes Claros, M G. E-mail: imenegali@yahoo.com.br
} 


\section{INTRODUÇÃO}

O Brasil tem uma das aviculturas comerciais mais desenvolvidas no mundo; além disso se destaca, ainda, como uma das principais atividades desenvolvidas em pequenas propriedades sendo responsável, também, portanto, pela geração de aproximadamente 4 milhões de empregos diretos no Brasil (UBABEF, 2011); no entanto, percebe-se que diversos aspectos da produção de frangos precisam ser melhorados a fim de que todos os segmentos envolvidos sejam devidamente beneficiados.

Durante a fase de criação de frangos de corte vários autores verificaram que o ambiente interno em que estão inseridos tanto os frangos como os trabalhadores, é composto por vários fatores, dentre os quais os físicos, químicos e biológicos, que incluem o ambiente aéreo, luz, ruído e componentes construtivos. Em alguns casos devido ao sistema de manejo adotado, esses componentes podem atingir níveis prejudiciais, em razão de sistema se manejo adotado e por serem considerados os principais fatores de risco para a saúde dos tratadores (Menegali et al., 2009; Vigoderis et al., 2010; Carvalho et al., 2011; Saraz et al., 2011).

Além disto, torna-se conveniente, durante os meses mais frios, para se manter a temperatura interna do aviário em níveis adequados à sobrevivência e produtividade do lote e manter o bem-estar do trabalhador, a adoção de técnicas, como a ventilação mínima, cujo objetivo é renovar o ar interno e controlar a concentração de gases, poeira e vapor d'água produzidos. No Brasil, os sistemas de ventilação mínima mais utilizados são os de pressão positiva, negativa e natural (Menegali et al., 2010).

Durante a realização do manejo de um galpão os trabalhadores executam atividades que demandam força e posturas inadequadas. De acordo com Silva et al. (2010) posturas desfavoráveis geram aumento de fadiga no trabalhador ocasionando, ao longo do tempo, lesões graves.

Objetivou-se, então, avaliar os fatores ergonômicos e realizar a análise postural e biomecânica dos trabalhadores durante a fase de aquecimento de frangos de corte criados distintamente, em galpões equipados com 3 diferentes sistemas de ventilação mínima.

\section{Material e mÉtodos}

O trabalho foi realizado em três aviários de frangos de corte similares de um mesmo núcleo produtivo, durante a estação de inverno. Os galpões estão localizados em uma região do Brasil na qual as quatro estações do ano são muito bem definidas, com inverno seco e baixas temperaturas e verão quente e chuvoso.

A granja pertence a um sistema de integração de empresa comercial, representativa de grande parte da avicultura industrial do Brasil. Ressalta-se que esta atividade é desenvolvida por pessoas de um mesmo grupo, ou seja, laços familiares, domésticos e, sobretudo, conhecidos, o que favorece a divisão das atividades tornando a avicultura de ordem familiar um negócio de sucesso.
Foram utilizadas aves da linhagem AVIAN (machos) originárias de um mesmo incubatório com a quantidade de 8.500 aves por galpão totalizando a densidade de 11 aves $\mathrm{m}^{-2}$. As práticas de manejo das aves seguiram as orientações técnicas habitualmente utilizadas pela empresa e identicamente por um mesmo tratador em todos os galpões.

Cada galpão foi equipado com um tipo de sistema de ventilação mínima (negativa, natural e positiva) no intuito de renovar o ar e promover uma ventilação higiênica, realizada principalmente na época do inverno; já no galpão 1 o sistema de ventilação utilizado foi o negativo (SVN); no galpão 2 a ventilação utilizada foi a natural (SVnat) e o galpão 3 foi equipado com ventiladores que empurravam e movimentavam o ar de dentro para fora do galpão, com pressão positiva (SVP).

A ventilação mínima foi baseada nos dados, segundo ASAE (2003) para galpões com sistema de aquecimento de combustão localizado internamente nas instalações, conforme Tabela 1.

Tabela 1. Programação do período de funcionamento dos sistemas de ventilação mínima para os sistemas de pressão negativa (SVM N) e pressão positiva (SVM P) para a fase de aquecimento

\begin{tabular}{cccc}
\hline \multirow{2}{*}{ Semanas } & \multicolumn{2}{c}{ Tempo (min)* } & Renovações \\
\cline { 2 - 3 } & Ligado & Desligado & \\
Primeira & 1 & 10 & 6 min ligados em $1 \mathrm{~h}$ \\
Segunda & 1 & 8 & 7 min ligados em $1 \mathrm{~h}$ \\
Terceira & 1 & 7 & 8 min ligados em $1 \mathrm{~h}$ \\
\hline * Tempo de funcionamento ligado/desligado foi o mesmo para os dois sistemas (SVMN e SVMP)
\end{tabular}

Os efeitos que os sistemas de ventilação proporcionaram ao ambiente foram avaliados durante a fase de crescimento inicial dos frangos de corte, também denominada fase de pinteiro, compreendendo o período de 1 a 21 dias.

Em cada galpão foram distribuídas três campânulas tipo asa de morcego, que eram abastecidas a cada $4 \mathrm{~h}$ com lenha, de maneira a manter a uniformidade no aquecimento. $\mathrm{O}$ abastecimento das campânulas era manual acompanhando as exigências ambientais térmica das aves, que mudam com a idade.

A carga de trabalho físico foi avaliada por intermédio do levantamento da frequência cardíaca nas diversas etapas do manejo do galpão. Os dados foram coletados e analisados pelo sistema da polar eletro. $\mathrm{O}$ equipamento é formado por um receptor digital de pulso, uma correia elástica e um transmissor com eletrodos que foram fixados na altura do tórax do trabalhador, por meio de uma correia elástica. Os batimentos cardíacos foram armazenados no receptor de pulso em intervalos de $15 \mathrm{~s}$. O polar era colocado nos trabalhadores no início da jornada, às $7 \mathrm{~h}$, e retirado no final do expediente, às 17 $\mathrm{h}$, inclusive permanecendo durante as pausas para higiene, almoço e descanso.

Após a coleta de dados os valores foram transferidos para o computador com a utilização da interface que acompanha o equipamento e, por intermédio de software específico, foram realizadas as análises. Com esses dados foi possível determinar a carga de trabalho físico imposta por cada atividade e estabelecer os limites aceitáveis para um desempenho contínuo no trabalho. Tal classificação laboral foi baseada na metodologia proposta por Apud (1999) demonstrada na Tabela 2. 
Tabela 2. Classificação da carga física de trabalho segundo a frequência cardíaca média de trabalho

\begin{tabular}{lc}
\hline \multicolumn{1}{c}{ Carga física de trabalho } & Frequência cardíaca em bpm \\
Muito leve & $<75$ \\
Leve & $75-100$ \\
Moderadamente pesada & $100-125$ \\
Pesada & $125-150$ \\
Pesadíssima & $150-175$ \\
Extremamente pesada & $>175$ \\
\hline
\end{tabular}

Com base nessas informações foi possível calcular a carga cardiovascular no trabalho (Apud, 1999), dada em bpm (batimentos por min) que corresponde à frequência cardíaca máxima utilizável. O valor desta carga foi calculado pela Eq. 1.

$$
\mathrm{CCV}=[(\mathrm{FCT}-\mathrm{FCR}) \div(\mathrm{FCM}-\mathrm{FCR})] \times 100
$$

em que:

$\mathrm{CCV}$ - carga cardiovascular, em \%

FCT - frequência cardíaca de trabalho, em bpm

FCR - frequência cardíaca de repouso, em bpm

FCM - frequência cardíaca máxima (220 - idade do trabalhador)

Com vista à realização de um trabalho contínuo sem riscos para a saúde, a carga cardiovascular, segundo Apud (1999) não deve ser superior a $40 \%$ em um turno de trabalho de $8 \mathrm{~h}$ casos em que, tendo a carga cardiovascular sido superior a este valor, calculou-se a frequência cardíaca limite (FCL) através da Eq. 2.

$$
\mathrm{FCL}=0,40 \mathrm{X}(\mathrm{FCM}-\mathrm{FCR})+\mathrm{FCR}
$$

Nas análises em que a carga cardiovascular ultrapassou este o valor de $40 \%$ para reorganização do trabalho, determinouse o tempo de repouso necessário (Eq. 3):

$$
\operatorname{Tr}=[\mathrm{Ht} \times(\mathrm{FCT}-\mathrm{FCL})] \div(\mathrm{FCT}-\mathrm{FCR})
$$

em que:

$\operatorname{Tr}$ - tempo da pausa, min

Ht - duração de trabalho, em min

A carga física de trabalho foi classificada de acordo com a frequência cardíaca de trabalho (Tabela 2).

Para a coleta de dados do ambiente térmico foi utilizado um termômetro digital de IBUTG (Índice de bulbo úmido e termômetro de globo) da marca Wibget, modelo RSS-214, programado para coletar os dados a cada $15 \mathrm{~min}$. O aparelho foi posicionado no centro geométrico de cada galpão, na altura correspondente à média dos tórax dos trabalhadores e programado para registrar as temperaturas de bulbo seco, bulbo úmido e globo negro. O equipamento foi instalado para coletar os dados a partir da chegada dos animais até completar os 21 dias de vida das aves.

O IBUTG foi calculado por meio da Eq. 4, adequado para avaliação de ambientes internos (sem carga solar) de acordo com o estabelecido pela NR 15 (2008):

$$
\text { IBUTG }=0,7 \mathrm{tbn}+0,3 \mathrm{tg}
$$

em que:

tbn - temperatura de bulbo úmido natural, ${ }^{\circ} \mathrm{C}$

$\operatorname{tg}$ - temperatura de globo, ${ }^{\circ} \mathrm{C}$

Os valores de IBUTG obtidos, obtidos na Tabela 4, foram confrontados com aqueles considerados limites tolerantes, por intermédio da Tabela 3.

Tabela 3. Taxas de metabolismo por tipo de atividade

\begin{tabular}{lc}
\hline Tipo de atividade & $\mathrm{kcal} \mathrm{h}^{-1}$ \\
$\begin{array}{l}\text { Sentado em repouso } \\
\text { Trabalho leve }\end{array}$ & 100 \\
$\begin{array}{l}\text { Sentado, movimentos moderados com braços e tronco } \\
\text { (ex: datilografia) }\end{array}$ & 125 \\
$\begin{array}{l}\text { Sentado, movimentos moderados com braços e pernas } \\
\text { (ex: dirigir) }\end{array}$ & 150 \\
$\begin{array}{l}\text { De pé, trabalho leve, em máquinas ou bancada, } \\
\text { principalmente com braços }\end{array}$ & 150 \\
$\begin{array}{l}\text { Trabalho moderado } \\
\text { Sentados, movimentos vigorosos com braços e pernas }\end{array}$ & 180 \\
$\begin{array}{l}\text { De pé, trabalho leve em máquina ou bancada, com alguma } \\
\text { movimentação }\end{array}$ & 175 \\
$\begin{array}{l}\text { De pé, trabalho moderado em máquina ou bancadacom } \\
\text { alguma movimentação }\end{array}$ & 220 \\
Em movimento, trabalho moderado de levantar ou empurrar & 300 \\
$\begin{array}{l}\text { Trabalho pesado } \\
\text { Trabalho intermitente de levantar, empurrar ou arrastar } \\
\text { pesos }\end{array}$ & 440 \\
Trabalho fatigante & 550 \\
\hline Fonte: NR 15 (MTE, 2008) &
\end{tabular}

Tabela 4. Limites de tolerância para trabal hos intermitentes com períodos de descanso no próprio local de trabalho em índice de bulbo úmido e termômetro de globo - IBUTG $\left({ }^{\circ} \mathrm{C}\right)$

\begin{tabular}{lccc}
\hline Regime de trabalho intermitente & \multicolumn{3}{c}{ Tipo de atividade } \\
\cline { 2 - 4 } \multicolumn{1}{c}{ com descanso no próprio local trabalho $\left(\mathbf{h}^{-1}\right)$} & Leve & Moderada & Pesada \\
Trabalho contínuo & até 30,0 & até 26,7 & até 25,0 \\
45 min de trabalho & 30,1 a & 26,8 a 28,0 & 25,1 a \\
15 min de descanso & 30,6 & & 25,9 \\
30 min de trabalho & 30,7 a & 28,1 a 29,4 & 26,0 a \\
30 min de descanso & 31,4 & 27,9 \\
15 min de trabalho & 31,5 a & 29,5 a 31,1 & 28,0 a \\
45 min de descanso & 32,2 & 30,0 \\
Não é permitido o trabalho sem a & acima da & acima de & acima de \\
adoção de medidas adequadas de & 32,2 & 31,1 & 30,0 \\
controle & & & \\
\hline Fonte: NR 15 (MTE, 2008) & &
\end{tabular}

Para avaliação da qualidade do ar no interior dos galpões foram feitas medições de concentrações instantâneas de amônia $\left(\mathrm{NH}_{3}\right)$ em ppm. As medições das concentrações de $\mathrm{NH}_{3}$ foram feitas no centro da instalação a $1,60 \mathrm{~m}$ de altura, considerada a altura média dos trabalhadores. As coletas de gases foram realizadas às $3,9,15$ e às $21 \mathrm{~h}$. Para determinar a concentração de $\mathrm{NH}_{3}$ utilizou-se o sensor com princípio eletroquímico, com resolução de 1 ppm e precisão de \pm 1 ppm, capaz de detectar a concentração instantânea em uma faixa de medição de 0 a 100 ppm. 
Os níveis de ruído do ambiente de trabalho foram obtidos por um aparelho dosí metro digital portátil, da marca Cirrus, projetado para atender aos requerimentos das normas sobre exposição a níveis de ruído. A dosagem propriamente dita dos níveis de ruído foi captada por um sensor denominado dosiBadge, fixado na gola da camisa do trabalhador, o mais próximo possível de sua zona auditiva, sendo os dados registrados a cada minuto durante a jornada de trabalho. $\mathrm{O}$ dosiBadge foi colocado na roupa do trabalhador às $7 \mathrm{~h}$ e retirado às $17 \mathrm{~h}$. Com os dados descarregados no computador cada atividade de manejo foi avaliada separadamente para verificação da intensidade do nível de ruído de que cada uma.

Os níveis de iluminação foram coletados por meio de luxímetro digital, modelo LDR-380, com precisão de $\pm 5 \%$ (5 dígitos) e resolução de 0,01 lux. As leituras foram feitas posicionando-se a base da fotocélula num plano horizontal na altura do local de trabalho, obtendo-se a leitura em lux. Os dados foram coletados às $3,9,15$ e 21 h com o intuito de verificar se o programa de luz adotado pela Empresa, a qual busca incentivar o desenvolvimento das aves, pode vir a prejudicar a realização das atividades de manejo.

Várias empresas utilizam o programa de luz recomendado por Albino (1998) em que na primeira semana de vida das aves o animal deve ficar exposto a $24 \mathrm{~h}$ de luz ininterruptas enquanto nas segunda e terceira semanas a exposição deve ser de 5 lux.

Para avaliar as posturas adotadas pelos funcionários durante a jornada de trabalho, foi utilizado o método OWAS (Ovako Working Posture Analysing System) criado pela OVAKO OY em conjunto com o Instituto Filandês de Saúde Ocupacional, na Finlândia, com o objetivo de analisar posturas de trabalho na indústria do aço (Vosniak et al., 2011).

Neste programa as posturas foram analisadas a partir das informações observadas em registros fotográficos do indivíduo durante a situação real de trabalho. No programa computacional OWAS foi preenchida a posição em que o tronco, braços e pernas estavam durante a adoção de determinada posição, além da informação sobre a estimativa do peso e direção da força que a pessoa estava executando.

O programa computacional relaciona as posturas com os membros do corpo atribuindo valores e um código de seis dígitos; o primeiro dígito do código indica a posição das costas, o segundo a posição dos braços, o terceiro, das pernas, o quarto indica levantamento de carga ou uso de força e os quinto e sexto, a fase de trabalho. Com a combinação das posições das costas, braços, pernas e o uso de força no método OWAS foi possível categorizar níveis de ação para medidas corretivas.

O método classificou, então, as posturas em 4 categorias:

$1^{\circ}$ - postura normal, que dispensa cuidados

$2^{\circ}$ - postura que deverá ser verificada durante a próxima rotina de trabalho $3^{\circ}$ - postura que deve merecer atenção, a curto prazo

$4^{\circ}$ - postura que deve merecer atenção imediata

Para avaliar os riscos de lesão no ombro, cotovelo, dorso, coxofemoral, joelho e tornozelo, realizou-se a avaliação biomecânica. O software Michigan, desenvolvido pela Universidade de Michigan, nos Estados Unidos, foi o utilizado para realizar a análise dos registros fotográficos feitos com o trabalhador em diversos ângulos e posições, durante a realização de suas atividades e as cargas envolvidas.

O software Michigan é um programa computacional de modelo biomecânico bidimensional de predição de posturas adotadas durante a realização das atividades e de forças estáticas, exigidas para sua realização. A análise dos resultados fornecidos por este software permite estabelecer a carga-limite recomendada, que corresponde ao peso que mais de $99 \%$ dos homens e $75 \%$ das mulheres conseguem levantar. O programa informa, ainda, o risco de lesão no disco L5/S1 da coluna a partir do peso em Newtons $(\mathrm{N})$ que esta vértebra pode suportar.

$\mathrm{Na}$ fase de aquecimento, em que são foram analisados estatisticamente apenas os dados relacionados ao IBUTG, os tratamentos foram dispostos em esquemas fatoriais envolvendo três sistemas de ventilação dos aviários, quatro horários de leitura dos valores do índice $(3,9,15$ e 21$)$ e três semanas $\left(1^{\mathrm{a}}, 2^{\mathrm{a}}\right.$ e $3^{a}$ ). No caso de significância os efeitos dos sistemas de ventilação e das semanas foram estudados pelo teste de Tukey, a 0,05 de probabilidade e os efeitos dos horários de leitura dos dados foram estudados pela análise de regressão selecionandose as equações para representar os dados por meio do comportamento biológico da variável, do valor do coeficiente de determinação $\left(\mathrm{R}^{2}\right)$ e da significância dos coeficientes do modelo.

A carga física de trabalho, qualidade do ar, nível de ruído, iluminação,biomecânica e análise postural, foram estudados confrontando-se as médias obtidas com os limites estabelecidos pela NR 15 do Ministério do Trabalho e Emprego, além da NBR 5413 (ABNT, 1992); desta forma, referidos fatores não foram submetidos a análise de variância.

\section{RESULTADOS E DISCUSSÃO}

Calculou-se a carga cardiovascular a partir do uso das equações 1, 2 e 3, e classificadas de acordo com a Tabela 2; verifica-se então, na Tabela 5 , que atividades como a chegada dos pintinhos e pesagem dos frangos foram classificadas leves.

No caso da chegada dos pintinhos a frequência cardíaca média do trabalho foi de $94 \mathrm{bpm}$, que permitiu classificar a atividade como leve, devido ao fato de ter sido realizada por no mínimo 3 pessoas e em curto período de tempo (máximo de $2 \mathrm{~h}$ ). Durante a pesagem dos frangos a frequência cardíaca média

Tabela 5. Carga cardiovascular exigida para a realização das atividades de manejo na granja

\begin{tabular}{lccccccc}
\hline \multicolumn{1}{c}{ Atividade } & CCV & FCT & FCL & FCR & FCM & Carga física de trabalho & Tempo de exposição \\
Chegada dos pintinhos & 21 & 94 & 114 & 70 & 182 & Leve & $2 \mathrm{~h} \mathrm{e} 10 \mathrm{~min}$ \\
Manejo da granja & 20 & 85 & 109 & 60 & 182 & Leve & $24 \mathrm{~h}$ \\
Pesagem dos frangos & 17 & 81 & 93,6 & 70 & 187 & Leve & $1 \mathrm{~h}$ \\
Revolvimento da cama & 50 & 129 & 109 & 60 & 182 & Pesada & $1 \mathrm{~h} \mathrm{e} 40 \mathrm{~min}$ \\
\hline
\end{tabular}

CCV - carga cardiovascular; FCT - frequência cardíaca de trabalho; FCL - frequência cardíaca limite; FCR - frequência cardíaca de repouso; FCM - frequência cardíaca máxima 
do trabalhador foi de $81 \mathrm{bpm}$; acredita-se que este valor tenha sido decorrente da pequena quantidade de aves que eram pesadas, em torno de 100 animai, com média de 152, 354 e $751 \mathrm{~g}$ cada ave, durante as primeira, segunda e terceira semanas, respectivamente. A pega dos frangos era manual, feita com calma, demorava em torno de 30 min e com o auxílio de uma segunda pessoa; devido a este comportamento dos trabalhadores a atividade foi classificada leve.

As atividades de manejo, como limpeza dos bebedouros, abastecimento dos comedouros e revolvimento da cama, eram feitas manualmente; mesmo assim e apesar de exigir um esforço físico considerável foram classificadas leve devido ao grande número de pausas realizadas e à forma lenta com que os trabalhadores as executavam. Este comportamento amenizou o esforço exigido pelas atividades e possibilitou uma frequência cardíaca média de $85 \mathrm{bpm}$.

O revolvimento da cama foi classificado pesado; acreditase que tal classificação foi devida à velocidade com que a atividade era executada, à condição da cama, que com o passar dos dias ficava mais pesada e ao equipamento utilizado no revolvimento (pá) que não tornava a tarefa eficiente. A frequência cardíaca média registrada para esta atividade foi de 129 bpm e a carga cardiovascular foi de $50 \%$, o que determina que o trabalhador deve atender a um regime de pausas para amenizar os eventuais problemas de saúde que possa vir a ter. $\mathrm{Na}$ atividade classificada pesada é comum o trabalhador sentirse fatigado podendo queixar-se de câimbras, dores musculares, tremores, distúrbios de sono, além de ser acometido por distúrbios músculo-ligamentares como distensão e tendinites (Silva et al., 2010). Assim e de acordo com o cálculo do tempo de repouso (Eq. 3) e independente do tempo de realização da atividade, o trabalhador necessita então de $25 \mathrm{~min}$ de descanso para cada 35 min trabalhados NR 15 (MTE, 2008).

A análise de variância dos dados relativos ao IBUTG na fase de pinteiro revelou que as fontes de variação semana $(S)$, Horário (H) e sistemas de ventilação (SV) além das interações $\mathrm{S}$ x He Hx SV, foram significativas (Tabela 6).

O desdobramento da interação Semana x Horário, mostrou diferenças significativas entre os valores médios de IBUTG nos horários de $3 \mathrm{e} 21 \mathrm{~h}$,com valores decrescentes da semana 1 para a semana 3; nos demais horários estudados ( 9 e 15 h) não houve diferença entre os resultados de IBUTG relativos às 3 semanas (Tabela 7).

De acordo com a recomendação da NR 15 (2008) no período entre 9 e 15 h o manejo da granja é considerado pesado, de acordo com a Tabela 3 e expõe o tratador a condições de sobrecarga térmica; além disto, os valores recomendados pela Norma são estabelecidos para uma jornada de $8 \mathrm{~h}$ de trabalho;
Tabela 6. Resumo da análise de variância dos dados relativos ao índice de bulbo úmido e termômetro de globo (IBUTG ) emgranjas de frangos de corte, nas fases de pinteiro

\begin{tabular}{lrc}
\hline \multicolumn{1}{c}{ FV } & GL & QM \\
Semana (S) & 2 & $60,9715^{* *}$ \\
Horário (H) & 3 & $827,1037^{* *}$ \\
Sistema de ventilação (SV) & 2 & $152,3488^{* *}$ \\
S x H & 6 & $10,4821^{* *}$ \\
S x SV & 4 & $2,6308 \mathrm{~ns}$ \\
H x SV & 6 & $9,5907^{* *}$ \\
S X SV xH & 12 & $0,4548 \mathrm{~ns}$ \\
Resíduo & 216 & 2,0761 \\
CV (\%) & \multicolumn{2}{c}{6,20} \\
\hline
\end{tabular}

**, * Significativo a nivel de 0,05 de probabilidade, respectivamente, ns - não significativo pelo teste $\mathrm{F}$

no entanto, o manejo da granja durante a fase de aquecimento exige, por parte do trabalhador, dedicação de $24 \mathrm{~h}$; desta forma, a adoção de pausas é necessária para restabelecimento das condições físicas e orgânicas, a não ser que haja revezamento de trabalhadores.

O estudo dos efeitos dos horários dentro de cada semana revelou que, independente da semana estudada, os valores de IBUTG tiveram ajuste em modelos quadráticos apresentando valores crescentes das 3 até aproximadamente as $15 \mathrm{~h}$ e decrescentes até as $21 \mathrm{~h}$ (Figura 1).

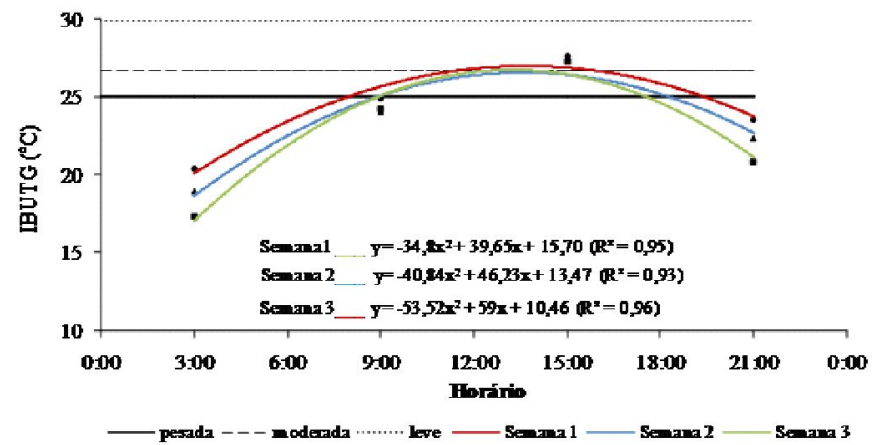

Figura 1. Variação do Índice de bulbo úmido e termômetro de globo (IBU TG ) em função dos horários estudados, dentro de cada semana na fase de pinteiro e respectivos níveis limites, de acordo com a classificação da atividade

A partir da classificação feita com o auxílio das Tabelas 3 e 4, em que a atividade de manejo é considerada pesada e com as representações na Figura 1, verifica-se ainda que o trabalhador fica exposto às condições de sobrecarga térmica e física no período das 9 até as $18 \mathrm{~h}$, independente da semana avaliada.

De acordo Fiedler \& Venturoli (2002) os trabalhadores que executam trabalhos considerados pesados merecem atenção

Tabela 7. Valores médios de índice de bulbo úmido e termômetro de globo (IBU TG ) em granjas de frangos de corte na fase depinteiro, de acordo com a interação Semana x Tempo, assim comotempo de permanência, classificação da atividade e IBUTG limite

\begin{tabular}{cccccccc}
\hline Semana & \multicolumn{4}{c}{ Tempo $(\mathbf{h})$} & $\begin{array}{c}\text { Tempo de } \\
\text { permanência }\end{array}$ & $\begin{array}{c}\text { Classificação da atividade } \\
\text { de acordo com Tabela } \mathbf{3}\end{array}$ & $\begin{array}{c}\text { IBUTG }\left({ }^{\circ} \mathrm{C}\right) \text { de acordo com } \\
\text { Tabela } \mathbf{4}\end{array}$ \\
\cline { 2 - 5 } & $\mathbf{0 3 : 0 0}$ & $\mathbf{0 9 : 0 0}$ & $\mathbf{1 5 : 0 0}$ & $\mathbf{2 1 : 0 0}$ & & 25 \\
2 & $20,37 \mathrm{a}$ & $24,91 \mathrm{a}$ & $27,66 \mathrm{a}$ & $23,50 \mathrm{a}$ & $12 \mathrm{~h}$ & Pesado & 25 \\
3 & $18,97 \mathrm{~b}$ & $24,01 \mathrm{a}$ & $27,48 \mathrm{a}$ & $22,31 \mathrm{~b}$ & $12 \mathrm{~h}$ & Pesado & 25 \\
\hline
\end{tabular}


Tabela 8. Valores médios de índice de bulbo úmido e termômetro de globo (IBU TG) em granjas de frangos de corte na fase de pintei ro de acordo com a interação Sistema de ventilação x H orário, assim como tempo de permanência, classificação da atividade e IBUTG limite

\begin{tabular}{cccccccc}
\hline Sistema de & \multicolumn{4}{c}{ Tempo (h) } & $\begin{array}{c}\text { Tempo de } \\
\text { permanência }\end{array}$ & $\begin{array}{c}\text { Classificação de acordo } \\
\text { com Tabela 5 }\end{array}$ & $\begin{array}{c}\text { IBUTG }\left({ }^{\circ} \mathrm{C}\right) \text { de acordo } \\
\text { com Tabela } \mathbf{6}\end{array}$ \\
\cline { 2 - 5 } ventilação & $\mathbf{3}$ & $\mathbf{9}$ & $\mathbf{1 5}$ & $\mathbf{2 1}$ & $12 \mathrm{~h}$ & Pesado & 25 \\
SVN & $17,57 \mathrm{~b}$ & $23,21 \mathrm{~b}$ & $25,79 \mathrm{c}$ & $20,63 \mathrm{~b}$ & $12 \mathrm{~h}$ & 25 \\
SVNat & $19,35 \mathrm{a}$ & $24,95 \mathrm{a}$ & $26,90 \mathrm{~b}$ & $22,62 \mathrm{a}$ & $12 \mathrm{~h}$ & Pesado & 25 \\
SVP & $19,74 \mathrm{a}$ & $24,96 \mathrm{a}$ & $29,78 \mathrm{a}$ & $23,39 \mathrm{a}$ & $12 \mathrm{~h}$ & Pesado & 25 \\
\hline
\end{tabular}

SVN - Sistema de ventilação negativa, SVNat - Sistema de ventilação natural, SVP - Sistema de ventilação positiva

especial quanto aos fatores ergonômicos ambiente de trabalho, alimentação e as pausas, pois estão sujeitos ao maior desgaste físico durante o trabalho.

As atividades classificadas moderadas têm seu desempenho comprometido no período em torno das 11 até as $15 \mathrm{~h}$, por serem realizadas em ambientes considerados insalubres termicamente.

Constatou-se, estudando os efeitos dos sistemas de ventilação em cada horário analisado, que o desdobramento da interação H x SV mostrou que no horário das 15 h os valores de IBUTG foram maiores no sistema de ventilação positiva (SVP) seguidos do sistema de ventilação natural (SVNat) e do sistema de ventilação negativa (SVN); nos demais horários os valores de IBUTG obtidos nos sistemas de ventilação SVP e SVNat foram equivalentes e superiores aos observados no sistema de ventilação SVN (Tabela 8).

Considerando o manejo da granja como atividade pesada verifica-se que, a partir das $9 \mathrm{~h}$, para os SVNat e SVP, os valores de IBUTG se aproximam do limite máximo recomendado pela NR 15 (MTE, 2008) de $25^{\circ} \mathrm{C}$ para uma jornada de $8 \mathrm{~h}$ de serviço. Os valores máximos de IBUTG foram registrados às $15 \mathrm{~h}$, independente do sistema de ventilação mínima adotado.

O estudo dos efeitos dos horários dentro de cada sistema de ventilação revelou que, semelhante ao verificado no desdobramento da interação S x H (Figura 2) os valores de IBUTG variaram de acordo com modelos quadráticos apresentando valores crescentes das 3 até em torno de $14 \mathrm{~h}$ e decrescentes até as $21 \mathrm{~h}$, independentemente do sistema de ventilação utilizado (Figura 2).

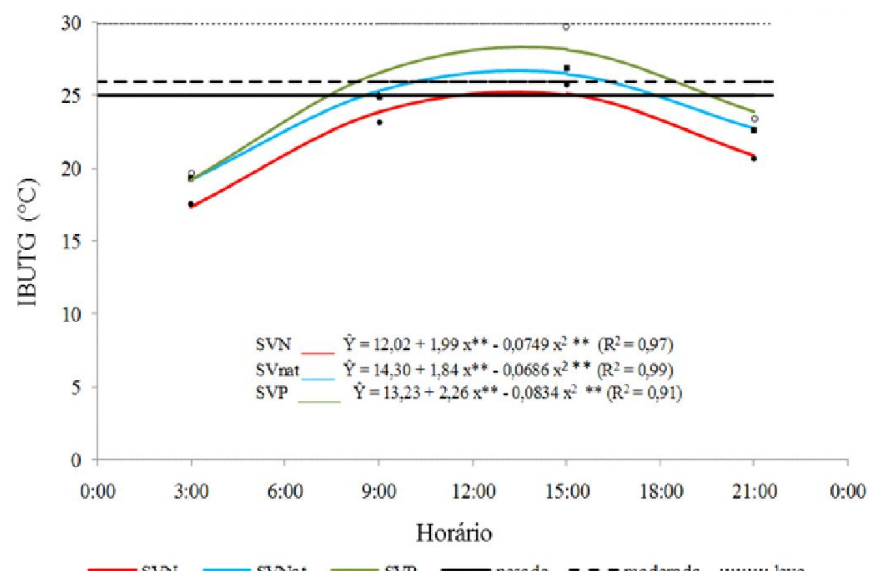

Figura 2. Variação do Índice de bulbo úmido e termômetro de globo (IBUTG ) em função dos horários estudados dentro de cada sistema de ventilação do galpão de frangos de corte na fase de pinteiro
De acordo com as curvas apresentadas na Figura 2, observa-se que o manejo da granja realizado nos galpões onde o sistema de ventilação é natural e positiva, expõe o trabalhador às condições insalubres termicamente no período em torno das 9 até as 18 h no SVNat e das 7 até as 2 h e 30 min no SVP.

Considerando que o manejo seja classificado moderado, os tratadores estariam expostos às sobrecargas térmica e física, no período das 10 às $16 \mathrm{~h}$, no SVNat e a partir das 9 até às $19 \mathrm{~h}$, no SVP.

Apesar do IBUTG se manter abaixo dos valores limites preconizados pela NR 15 (MTE, 2008) antes aproximadamente das $7 \mathrm{~h}$ e após as $20 \mathrm{~h}$, nesses horários os trabalhadores permanecem expostos a uma grande variação de temperatura (choque térmico) devido ao fato de entrarem e sair do galpão, principalmente no período da madrugada para realizar o abastecimento e manutenção das campânulas, praticamente de $3 \mathrm{em} 3 \mathrm{~h}$; desta forma, os trabalhadores ficam sujeitos a poucas horas de sono podendo ainda desenvolver gripes ou resfriados; por outro lado, a variação de temperatura à qual os trabalhador estão expostos, é maior no SVN.

Na Figura 3 se apresentam os valores médios diários de concentração de amônia, coletados para cada um dos 21 dias experimentais (de 1 a 21 dias de idade das aves), para cada horário de observação, às 3, 9, 15 e $21 \mathrm{~h}$, para cada um dos diferentes sistemas de ventilação mínima (SVN, SVnat e SVP).

Verifica-se que nos horários das 3, 15 e 21 h, para os três diferentes tipos de ventilação mínima as concentrações de $\mathrm{NH}_{3}$ estiveram em níveis considerados inofensivos (menores que 20 ppm) valor que não interfere negativamente na qualidade do ar.

De acordo com a NR 15 (MTE, 2008) a concentração tolerável de amônia para humano é de 20 ppm para exposição de até $8 \mathrm{~h}$ de trabalho; no entanto, foi possível verificar que durante a coleta dos dados, quando os valores estavam acima de 10 ppm, a sensação de irritabilidade nos olhos e narinas era presente. Assim, o uso de máscaras é recomendável durante todo o período de realização de manejo no interior da granja, principalmente nos horários em que a concentração de amônia é mais elevada e o ambiente aéreo está insalubre.

Valores acima de 20 ppm levam o trabalhador a riscos de vertigens, queda na oxigenação sanguínea, agravamento de doenças respiratórias, intoxicação e vertigens (Fernandes \& Furlaneto, 2004; Faria et al., 2006). Contudo, verificou-se que os trabalhadores não faziam uso de máscaras para proteção quanto à inspiração de gases e poeira.

Valores acima de 20 ppm foram encontrados nos horários próximos às $9 \mathrm{~h}$, nos galpões equipados com SVN e SVNat; acredita-se que esta condição seja devida ao tempo em que o 


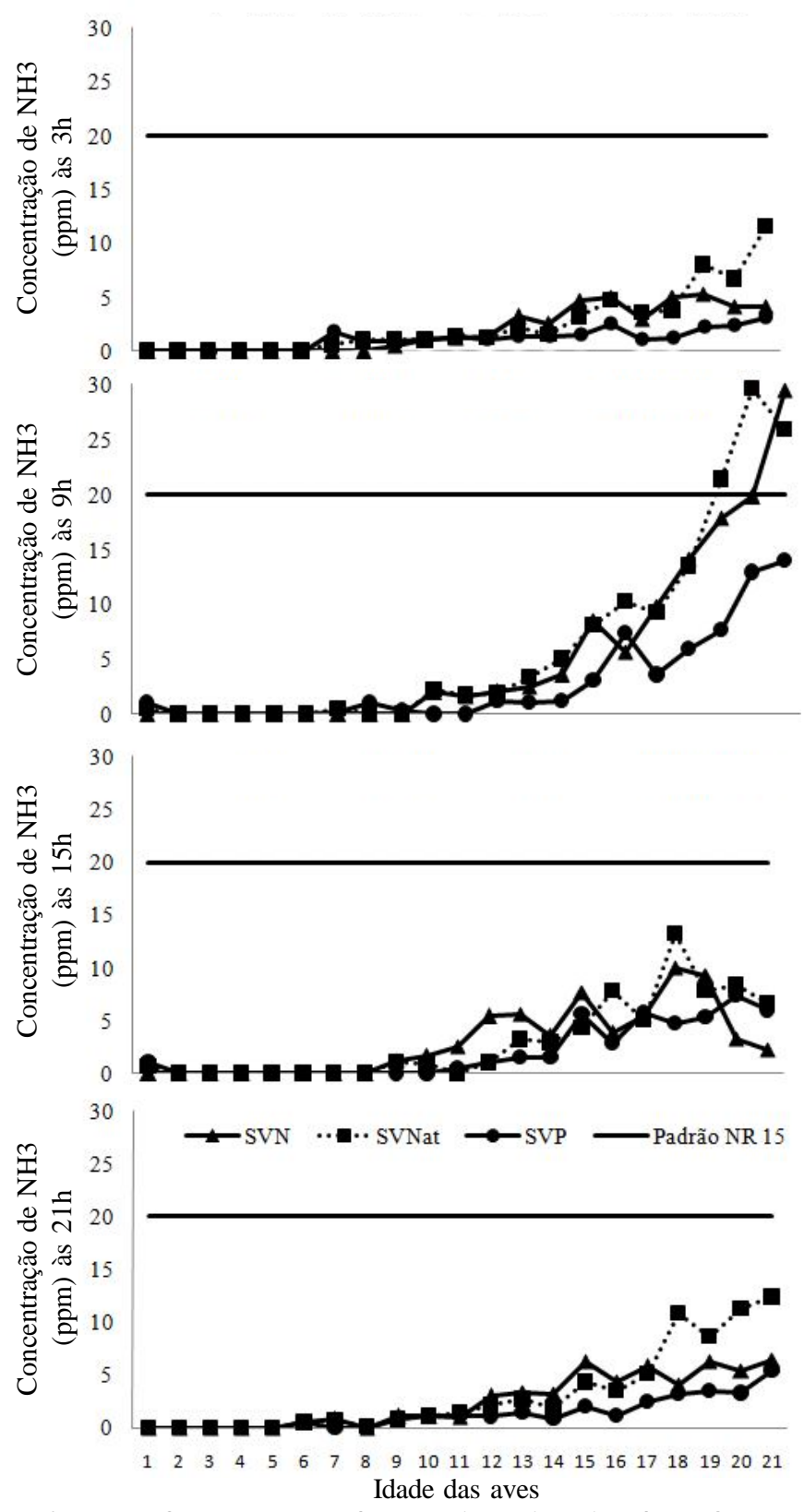

Figura 3. Concentração de amônia no interior dos gal pões na fase de pinteiro às $3,9,15$ e $21 \mathrm{~h}$, em função dos sistemas de ventilação, assim como o nível limite de acordo com os valores estabelecidos pela N R 15 (2008)

galpão ficou fechado durante a madrugada e é a partir deste horário que as cortinas começam a ser manejadas para a eliminação dos gases que se encontram no interior da instalação.

A partir das curvas de concentração de amônia demonstradas anteriormente, observa-se que o SVP foi o sistema que possibilitou os menores níveis de amônia.

Correlacionando a qualidade do ar com o ambiente térmico por meio dos resultados já apresentados, verifica-se, apesar do IBUTG ter sido maior no galpão com SVP, que a concentração de amônia foi menor nesses galpões condição que evidencia maior eficiência do sistema de ventilação que tem, como objetivo, renovar o ar sem reduzir a temperatura no interior do aviário.
Problemas com ruído foram verificados somente durante o corte da lenha para abastecimento das campânulas. O corte de lenha é feito com motosserra e o ruído verificado foi de $89 \mathrm{~dB}$ (A). De acordo com a NR 15 (MTE, 2008) o valor tolerável para $8 \mathrm{~h}$ de serviço é de $85 \mathrm{~dB}(\mathrm{~A})$; no caso em questão a atividade dura, em média, $40 \mathrm{~min}$; mesmo assim, o uso do protetor auricular é recomendável para evitar uma PAIR (perda auditiva induzida por ruído) e incômodos durante sua realização. Contudo, verificou-se que os trabalhadores não faziam uso de qualquer tipo de protetor auricular.

Condição semelhante foi encontrada por Damasceno et al. (2010) ao verificarem que em ponto interno algum dos galpões com aves alojadas e durante o vazio sanitário, os níveis de pressão sonora estiveram acima de $85 \mathrm{~dB}(\mathrm{~A})$.

De acordo com Moraes et al. (2008) a intensidade luminosa na altura do frango deve ser de 20 lux na primeira semana de vida e posteriormente de 5 lux embora, de acordo com a NBR 5413 (1992) a iluminação mínima no interior do aviário deva ser de 30 lux para o desenvolvimento das atividades, de forma segura para o trabalhador.

Observou-se, com base na Tabela 8 , que mesmo com a exposição direta de luz na primeira semana, a iluminação média para os três galpões às 3 h, foi de 4,8 luz e às 21 h de 4,9 lux, valores esses considerados aceitáveis, de conformidade com o recomendado pela NBR 5413; para que haja desenvolvimento das atividades de forma salubre, foram verificados às $9 \mathrm{~h}$ com a iluminação média de 66,6 lux e às $15 \mathrm{~h}$ foi de 92,5 lux, para os três galpões estudados.

Na Tabela 9 é possível observar a iluminação nas granjas em função das semanas estudadas e o tempo de exposição do trabalhador à intensidade de iluminação.

Tabela 9. Valores médios de iluminação (lux) encontrados nos galpões em função das semanas estudadas, assim como o tempo de exposição dos trabalhadores es valores recomendados pela ABNT (1992)

\begin{tabular}{|c|c|c|c|c|c|}
\hline \multirow{2}{*}{ Horário } & \multicolumn{3}{|c|}{ Semanas } & \multirow{2}{*}{$\begin{array}{l}\text { Tempo de } \\
\text { exposição }\end{array}$} & \multirow{2}{*}{$\begin{array}{c}\text { ABNT } \\
\text { (1992) }\end{array}$} \\
\hline & Primeira & Segunda & Terceira & & \\
\hline 3 & 4,8 & escuro & escuro & $1 \mathrm{~h}$ & 30 \\
\hline 9 & 66,6 & 119 & 147 & $1 \mathrm{~h}$ & 30 \\
\hline 15 & 92,5 & 159 & 194 & $1 \mathrm{~h}$ & 30 \\
\hline 21 & 4,8 & escuro & escuro & $1 \mathrm{~h}$ & 30 \\
\hline
\end{tabular}

Na segunda e na terceira semanas os animais passam por exposição à luz somente durante o dia no período noturno eles devem ficar totalmente no escuro, o que dificulta muito o trabalha do granjeiro que deve realizar o manejo dos aquecedores durante a madrugada, com o auxílio de uma lanterna, fato passível de resultar em riscos de queda e problemas na visão em virtude da realização dessas atividades no escuro. A iluminação média verificada para os três galpões às 9 h, foi de 119 lux e de 147 lux para as segunda e terceira semanas, respectivamente; às 15 h foi 159 lux e de 194 lux para a segunda e a terceira semanas, respectivamente.

De acordo com Damasceno et al. (2009) os níveis de luminosidade média durante o período diurno são os aceitáveis porém a iluminação noturna, proporcionada somente pelas lâmpadas dos galpões, é considerada baixa. Para o trabalhador 
da granja avícola a luminosidade do ambiente está bem abaixo do recomendado pela norma pertinente no País. O trabalho realizado em ambiente de baixa iluminação provoca problemas de fadiga visual, queda no desempenho e risco de acidentes.

Com relação à análise postural constatou-se que a postura adotada no manejo do galpão, classificada em categoria 2 e que necessita ser verificada a longo prazo, foi observada durante o carregamento de saco de carvão. Trata-se de uma atividade que não exige grandes esforços por parte do trabalhador, já que ele percorre pequenos trechos (máximo $5 \mathrm{~m}$ ) com o produto nas costas; a lenha é cortada no lado do galpão e conduzida para seu interior por meio de carrinhos de mão; este equipamento era abastecido várias vezes a fim de que o mesmo não se tornasse pesado.

As atividades classificadas na categoria 3, foram: o preenchimento do balde com ração e com casca de café para ser colocada na composteira e a pega de pintinhos para pesagem; para tais atividades a avaliação postural merece atenção a curto prazo visto que demandam maiores esforços e precisam ser realizadas de forma mais rápida.

As atividades que requerem ações corretivas imediatas por terem sido classificadas como categoria 4 foram identificadas durante as seguintes atividades: descarregamento de caixas com pintos vindos do incubatório, revolvimento da cama com o auxílio de enxada, abastecimento do comedouro infantil, tração de carrinho de ração e lenha, carregamento do saco com casca de café e lavagem do bebedouro. Esta classificação foi decorrente da aplicação de força, postura incorreta adotada pelos funcionários para realizar essas tarefas e velocidade na realização das mesmas.

Os problemas de saúde mais comuns em aviários estão relacionados a dores músculo-esqueléticas na região lombar, devido às atividades manuais de limpeza de bebedouros e comedouros (Alencar et al., 2006; Evangelista et al., 2012).

Em razão do esforço físico feito pelos trabalhadores na fase de pinteiro a análise de biomecânica evidenciou que durante o carregamento do carrinho com lenha para abastecer as campânulas, e de ração, para abastecer os comedouros, o trabalhador está exposto ao risco de lesão no ombro, cotovelo, disco L5/S1 (dorso) joelho e tornozelo.

$\mathrm{Na}$ pesagem dos frangos as articulações que podem ser acometidas são: ombro, cotovelo, disco L5/S1 (dorso) e coxofemoral. Outro problema verificadoé o risco de compressão no disco L5/S1 que, com o passar do tempo, tende a agravar as alterações degenerativas na coluna. De acordo com Apud (1999) se a força de compressão for maior que $3423 \mathrm{~N}$, existe um risco eminente para a saúde de grande parte dos trabalhadores provocando danos às estruturas anatômicas, sendo imprescindíveis a redução do tempo de exposição e o peso da carga.

Enquanto o trabalhador movimenta o carrinho de ração, que pesa em média $135 \mathrm{~kg}$, a força de compressão exigida pelo disco L5/S1 é em torno de $2290 \mathrm{~N}$; já durante o carregamento de saco de casca de café e de saco de frangos mortos para a composteira, além da pesagem de frangos, a força de compressão verificada foi de 2216, 1813 e $1858 \mathrm{~N}$, respectivamente.

\section{CONCLUSÕES}

1. Determinadas atividades desenvolvidas em um galpão merecem destaque por serem consideradas prejudiciais à saúde.

2. Enquanto realizam as atividades de manejo, os trabalhadores estão expostos à sobrecarga física, principalmente durante o abastecimento dos comedouros, de forma manual e tração dos carrinhos de ração.

3. Atividades como a tração do carrinho de mão com ração, abastecimento dos comedouros e limpeza dos bebedouros, expõem os trabalhadores ao risco de lesão em todas as articulações.

4. A adoção de métodos específicos de ergonomia pode contribuir para a redução de injúrias e melhoria na qualidade de vida dos trabalhadores de galpões avícolas.

\section{Agradecimentos}

À Fundação de Amparo à Pesquisado Estado de Minas Gerais (FAPEMIG), à CAPES (Coordenação de Aperfeiçoamento de Pessoal de Nível Superior), ao CNPq (Conselho Nacional de Desenvolvimento Científico e Tecnológico) e à Universidade Federal de Viçosa (UFV).

\section{LiTERATURA CITADA}

ABNT - Associação Brasileira de Normas Técnicas. Técnicas NBR 5413 Iluminação de interiores. Rio de Janeiro: ABNT, 1992. 13p.

Albino, L. F. T. Frango de corte: Manual prático de manejo e produção. Viçosa: Aprenda Fácil. 1998. 72p.

Alencar, M. C. B.; Nääs, I. A.; Salgado, D. D’A.; Gontijo, L. A. Mortalidade de frangos de corte e comportamento humano no trabalho. Scientia Agrícola, v.63, p.529-533, 2006.

Apud, E. Guidelines on ergonomic study in forestry. Genebra: ILO, 1999. 241p.

ASAE - American Society of Agricultural Engineers. Annual International Meeting. Las Vegas, 2003.

Carvalho, C. C. S.; Souza, C. F.; Tinôco, I. de F. F., Vieira, M. F. A.; Minette, L. J. Segurança, saúde e ergonomia de trabalhadores em galpões de frangos de corte equipados com diferentes sistemas de abastecimento de ração. Engenharia Agrícola, v.31, p.438-447, 2011.

Damasceno, F. A.; Yanagi Júnior, T.; Gomes, R. C. C.; Lima, R. R.; Schiassi, L.; Morais, S. R. P. Avaliação do nível de ruído produzido por caminhões de ração no município de Itaberaí (GO). Revista de Estudos Ambientais, v.4, p.44-48, 2009.

Damasceno, F. A.; Yanagi Júnior, T.; Lima, R. R.; Gomes, R. C. C.; Moraes, S. R. P. Avaliação do bem-estar de frangos de corte em dois galpões comerciais climatizados. Ciência e Agrotecnologia, v.34, p.1031-1038, 2010.

Evangelista, W. L.; Tinoco, I. de F. F.; Souza, A. P.; Minetti, L. J.; Baêta, F. C.; Silva, E. P.; Oliveira, L. A. Postural analysis of workers in a typical meat processing company in Brazil. Work: A Journal of Prevention, Assessment and Rehabilitation, v.41, p.5392-5394, 2012. 
Faria, N. M. X.; Facchini, L. A.; Fassa, A. G.; Tomasi, E. Trabalho rural, exposição a poeiras e sintomas respiratórios entre agricultores. Revista Saúde Pública, v.40, p.827-836, 2006.

Fernandes F. C.; Furlaneto, A. Riscos biológicos em aviários. Revista Brasileira de Medicina do Trabalho, v.2, p.140-152, 2004.

Fiedler, N. C.; Venturoli, F. Avaliação da carga física de trabalho exigida em atividades de fabricação de móveis no Distrito Federal. Revista Cerne, v.8, p.117-122, 2002.

Menegali, I.; Baeta, F. C.; Tinoco, I. de F. F.; Cordeiro, M. B.; Guimarães, M. C. C. Desempenho produtivo de frangos de corte em diferentes sistemas de instalações semiclimatizadas no sul doBrasil. Engenharia na Agricultura, v.18, p.461-471, 2010.

Menegali, I.; Tinoco, I. de F. F.; Baeta, F. C.; Cecon, P. R.; Guimarães, M. C. C.; Cordeiro, M. B. Ambiente térmico e concentrações de gases em instalações para frangos de corte no período de aquecimento. Revista Brasileira de Engenharia Agrícola eAmbiental, v.13, p.984-990, 2009.

Moraes, D. T.; Lara L. J. C.; Baião, N. C.; Cançado, S. N.; Gonzalez, M. L.; Aguilar, C. A. L.; Lana, A. M. Q. Efeitos do programa de luz sobre o desempenho, rendimento de carcaça e resposta imunológica em frangos de corte. Arquivo Brasileiro de Medicina Veterinária e Zootecnia, v.60, p.201-203, 2008.
MTE - Ministério do Trabalho e Emprego. NR 15 - Atividades e operações insalubres. In: Segurança e medicina do trabalho. São Paulo: Atlas, 2008. 82p.

Saraz, J. A. O.; Tinôco, I. de F. F.; Paula, M. O. de. Modeling and experimental validation to estimate the energy balance for a broiler house with misting cooling. Dyna, v.79, p.10-23, 2011.

Silva, E. P.; Cotta, R. M. M.; Souza, A. P. de; Minette, L. J.; Vieira, H. A. N. F. Diagnóstico das condições de saúde de trabalhadores envolvidos na atividade em extração manual de madeira. Revista Árvore, v.34, p.561-566, 2010.

Vigoderis, R. B.; Cordeiro, M. B.; Tinôco, I. de F. F.; Menegali, I.; Souza Júnior, J. P.; Holanda, M. C. R. Avaliação do uso de ventilação mínima em galpões avícolas e de sua influência no desempenho de aves de corte no período de inverno. Revista Brasileira de Zootecnia, v.39, p.1381-1386, 2010.

Vosniak, J.; Lopes, E. da S.; Inoue, M. T.; Batista, A. Avaliação da postura de trabalhadores nas atividades de plantio e adubação em florestas plantadas. Revista Ceres, v.58, p.584592, 2011.

UBABEF - União Brasileira de Avicultura. http:// www.abef.com.br/ ubabef, 2011. 